\title{
El ego y el cuerpo. El dilema de Descartes
}

\author{
VICENTE SANFÉLIX VIDARTE \\ Universidad de Valencia
}

EN PRIMER LUGAR QUISIERA AGRADECER a los organizadores de este homenaje al profesor Arregui el haberme invitado a participar en el mismo. Con Gorka me unía, amén de un afecto personal antiguo y sincero, un profundo respeto académico y una intensa simpatía intelectual.

Respeto, porque fue una persona que trabajó mucho por los demás, probablemente más que para sí mismo. Por sus alumnos, en primer lugar, pero también por sus compañeros. $\mathrm{Y}$ es que en un mundo tan propenso a la atomización y la dispersión como es el de los profesores universitarios de filosofía, Gorka siempre estuvo en la primera línea de muchos de los intentos por vertebrar nuestra profesión. Al respecto, aún recuerdo con emoción y agradecimiento sus desvelos para que el último congreso de la Sociedad hispánica de antropología filosófica saliera perfecto. O su esforzada presencia en Santiago de Compostela, hace ahora apenas un año, en el último congreso de la Sociedad académica de filosofía. Gorka era, todos lo sabíamos, una de esas personas con las que siempre se podía contar a la hora de arrimar el hombro.

Por lo que hace a mi simpatía intelectual hacia él tenía su origen en mi interés -en él sin duda pasión- por la filosofía de Wittgenstein en la que, como todos sabemos, era uno de nuestros mejores especialistas. Quizás por ello hoy tocara que yo, aquí, hablara del filósofo austriaco, pero si no lo voy a hacer es, en cierto modo, por fidelidad al mismo Gorka, pues cuando me escribió para anunciarme la celebración de este symposium creí entender que me sugería que hablase de Descartes.

En lo que a continuación viene voy a intentar precisar cuál fue la concepción cartesiana del yo y de su relación con el cuerpo. Procuraré hacer ver cómo una interpretación muy usual al respecto, tanto entre los defensores como entre los detractores del pensador francés, no termina de hacerle justicia, aunque desde ya mismo confieso que los textos cartesianos dan pie, por más de una razón, a que semejante interpretación resulte plausible. 
Lo que me mueve a esta empresa no es un mero interés arqueológico sino crítico. Si en la teoría cartesiana hay errores, detectarlos podría ayudarnos a afrontar mejor -no seré tan presuntuoso ni tan ingenuo como para decir resolver- aquel problema. Una vez más, y como siempre, repensar a los clásicos, que no por casualidad lo son, nos puede ayudar a pensar mejor. Entremos, pues, sin más dilación en nuestro asunto: ¿cuál es la tesis de Descartes a propósito de la naturaleza del yo y de su relación con el cuerpo?

Una interpretación muy usual, tanto que bien podríamos decir que es la que la historia efectual nos ha legado, viene a decir que Descartes se comprometió con una tesis reduccionista acerca del yo. Según la misma, aunque el ser humano sería un compuesto de dos sustancias, alma y cuerpo, misteriosamente unidas a través de la glándula pineal, el ego sólo sería el alma, no el cuerpo.

Como ya he adelantado, semejante interpretación no es gratuita. Tiene su razón de ser en muchos de los textos cartesianos. Por ejemplo, y para empezar, en esas pocas páginas, a mi parecer extremadamente oscuras y confusas, que este campeón de la claridad y la distinción nos legó en la segunda de sus Meditaciones metafísicas.

En ellas, como es bien sabido, comienza el pensador francés por establecer contra la duda hiperbólica la certeza indubitable de la existencia del ego: "esta proposición: yo soy, yo existo, es necesariamente verdadera, todas las veces que la pronuncio, o que la concibo en mi espíritu" (IX.19) ${ }^{1}$. En un pensador no excesivamente preocupado por la filosofía del lenguaje como es Descartes no deja de ser curioso el escrúpulo en la formulación de su primer principio: se nos advierte de que se trata de una proposición verdadera tan pronto como se pronuncia. $\mathrm{Y}$ es que su tesis se compadece bien con ciertos hechos semánticos.

En efecto, si es posible imaginar situaciones en que se utilice un "tú", o un "él" o "ella", sin que realmente exista un referente adecuado de tales expresiones, semejante eventualidad está excluida del uso del "yo" por parte de un hablante competente. Vemos ahora que el cartesianismo tiene raíces profundas en el suelo fecundo de nuestra gramática. Nietzsche lo comprendió y lo denunció. Pero habría que decirle a los nietzscheanos que tener la gramática del lado de uno es mucho tener y que, por el contrario, querer ir contra la gramática sitúa al propio pensamiento al borde del abismo del sin sentido.

1 Los números latinos remiten al volumen de la edición de Adam y Tannery de las obras de Descartes. Los arábigos a la página en que se encuentra la cita. 
Fuera como fuere, y volviendo a sumergirnos en el torrente de la meditación, parece que después de establecer esta primera verdad se lanza Descartes a la tarea de intentar precisar qué ${ }^{2}$ es ese ego pues, como confiesa el autor de las Meditaciones metafísicas, a esa altura de las mismas "yo, que estoy cierto que soy, no conozco aún bastante claramente lo que yo soy" (IX.19. Cf. también VII.25); inquisición que se cierra, apenas dos páginas después, con una celebérrima conclusión: "no soy, precisamente hablando, más que una cosa que piensa, es decir un espíritu, un entendimiento o una razón”. (IX.21).

Admitámoslo, por consiguiente: Descartes da pie para que se le atribuya -tanto por parte de sus detractores cuanto de sus defensores- la tesis de que el yo es una sustancia pensante, no un ser humano dotado de un cuerpo. De hecho, que el yo pudiera identificarse con algo corporal ha sido el primer prejuicio natural que el pensador francés ha despachado en el transcurso de su indagación (IX.21).

La conclusión positiva que Descartes extrae de toda esta reflexión, a saber: que ese yo de cuya existencia se está cierto no es (¡hablando con precisión!) sino una cosa que piensa, es decir un espíritu, una mente o un alma, un entendimiento o una razón (VII. 27 y IX. 21), es sumamente extraña, porque ¿quién podría reconocerse en semejante retrato? ¿Quién diría de sí que es sólo un espíritu, puro intelecto o razón? La extrañeza de esta conclusión nos obliga a preguntarnos por el argumento que puede haber conducido a Descartes hasta ella.

2 O quién, pues el texto original latino es ambiguo en este punto y tanto permite una interpretación/traducción cuanto la otra. En efecto, el texto latino reza: "Nondum verò satis intelligo, quisnam sim ego ille, qui jam necesario sum"; afirmación que tanto puede traducirse por "Pero yo no conozco aún bastante claramente lo que yo soy, yo que estoy cierto que soy" (de hecho, esta es la versión que daba la traducción francesa de las Meditaciones revisada y autorizada por el mismo Descartes: "Mais je ne connais pas encore assez clairement ce que je suis, moi qui suis certain que je suis". IX. 19) cuanto por, como vertió García Morente, "Pero yo, que estoy cierto de que soy, no conozco aún con bastante claridad quién soy". Y no cabe achacar el equívoco a los traductores. De hecho, en la misma versión francesa la cuestión por "lo que yo soy (ce que je suis)" va a dejar paso poco después a la pregunta por "quién soy yo (qui suis je)" (Cf. IX. 21), aunque la célebre respuesta final a todo el asunto parezca de nuevo contestar más bien a la interrogación por "qué es lo que yo soy (qu'est-ce que je suis)". (Cf. IX.22). Evidentemente, el texto cartesiano resulta tremendamente equívoco, pues no es lo mismo plantearse la cuestión qué soy, que interroga por una identidad genérica que puedo compartir con otros, que preguntarse quién soy, que interroga por una identidad numérica que no puedo compartir con nadie o, por decirlo escolásticamente, que resulta incomunicable. No obstante, hay en el pensamiento cartesiano razones para comprender que semejante equivocidad resulta, a la postre, irrelevante. 


\section{III}

En uno de sus escritos sobre Identidad y necesidad, Samuel Kripke ha atribuido a Descartes un argumento modal a favor del dualismo que, partiendo de la premisa de que él, Descartes, pudiera existir aun cuando su cuerpo no lo hiciera, concluye que él, Descartes, no es su cuerpo. Un argumento que, a pesar de su simplicidad, dice Kripke, es formalmente válido ${ }^{3}$.

3 Cf. S. Kripke, "Identity and Necessity" en S.P. Schwartz (Edt), Naming, Necessity and Natural Kinds. Ithaca. Cornell University Press. 1977. Este argumento "cartesiano" que Kripke presenta es difícilmente comprensible si no se tienen en cuenta las tesis del pensador norteamericano acerca de la necesidad de la identidad. Contra la posibilidad de los enunciados contingentes de identidad da las siguientes razones:

Primero, la ley de sustitución de los idénticos dice que, para cualesquiera objetos $x$ y $y$, si $x$ es idéntico a $y$, entonces si $x$ tiene una cierta propiedad $F$, también la tiene $y$ :

(1) $(\mathrm{x})(\mathrm{y})[(\mathrm{x}=\mathrm{y})>(\mathrm{Fx}>\mathrm{Fy})]$

Por otro lado, con toda seguridad cualquier objeto es necesariamente idéntico a sí mismo:

(2) $(\mathrm{x})(\mathrm{x}=\mathrm{x})$

Pero:

(3) (x) (y) (x=y) $>[(\mathrm{x}=\mathrm{x})>(\mathrm{x}=\mathrm{y})]$

es una instancia de sustitución de (1), esto es, de la ley de sustitución. A partir de (2) y (3), podemos concluir que, para toda $x$ y $y$, si $x$ es igual a $y$, entonces, es necesario que $x$ sea igual a $y$ :

(4) (x) (y) $[(\mathrm{x}=\mathrm{y})>(\mathrm{x}=\mathrm{y})]$

Esto es así porque la cláusula $(\mathrm{x}=\mathrm{x})$ del condicional, se elimina dado que se sabe que es verdadera.

Con esto en mente es fácil entender lo que sería el argumento modal "cartesiano": es posible -sería su primera premisa- que yo exista y que no exista mi cuerpo:

(I) $\diamond(\mathrm{Fa} \Delta \neg \mathrm{Fb})$

lo que, por la Interdefinición de implicación y conjunción, equivale a la posibilidad de que mi existencia no implique la existencia de mi cuerpo:

(II) $\diamond \neg(\mathrm{Fa}>\mathrm{Fb})$

lo que quiere decir, a su vez, que esta implicación no es necesaria:

(III) $\neg(\mathrm{Fa}>\mathrm{Fb})$

ahora bien, parece evidente que si a es necesariamente igual a b, entonces necesariamente si a existe, b existe:

$$
\text { (IV) }(\mathrm{a}=\mathrm{b})>(\mathrm{Fa}>\mathrm{Fb})
$$

pero por modus tollens de (IV) y (III) se sigue que:

(V) $\neg(\mathrm{a}=\mathrm{b})$

y por modus tollens de nuevo, ahora con (4), la conclusión del argumento de Kripke, una vez que se eliminan de ella los generalizadores, que mi yo es diferente de mi cuerpo:

$(\mathrm{VI})(\mathrm{a} \neq \mathrm{b})$

que era, en definitiva, lo que se trataba de demostrar.

Tenemos, pues, aquí un argumento modal formalmente válido -prescindamos de su corrección material- que demostraría la distinción del yo y el cuerpo. 
Por desgracia, Kripke no dice dónde da Descartes este argumento. Quizás esté aludiendo al Discurso del método. Desde luego, no se encuentra en la segunda Meditación, pues en ella escribe Descartes: "Pero ¿no podría ocurrir también que estas cosas, que yo supongo no ser en absoluto porque me son desconocidas, no fueran efectivamente diferentes de mí, que conozco? No lo sé" (IX.21).

Es decir, que Descartes reconoce que no ha demostrado taxativamente que el yo no sea un ser humano, un ser corpóreo por tanto. Y hace bien en conceder que su argumento no es conclusivo como según Kripke lo es el argumento modal que le atribuye porque, en definitiva, el argumento cartesiano que funciona en esta segunda meditación no consiste sino en decir que el yo no es el cuerpo porque de la existencia del yo estamos inconcusamente seguros pero de la de nuestro cuerpo no.

Se trata de una simple aplicación del principio de sustitución de los idénticos: si yo y mi cuerpo somos idénticos, toda propiedad que tenga yo la tiene mi cuerpo. Pero, y por esto hace bien Descartes en no conceder que su argumento sea concluyente, una aplicación ilegítima, puesto que este principio no puede aplicarse a propiedades intensionales. Y es que conceder que el hecho de que yo conozca inconcusamente mi existencia pero no la de mi cuerpo prueba que yo no soy mi cuerpo, sería como conceder que el hecho de que alguien sepa que Cicerón escribió el De natura deorum mientras ignora si Tulio lo escribió prueba que Cicerón y Tulio eran dos personas diferentes.

En sus respuestas a las quintas objeciones nos confirma Descartes en nuestra lectura: "en tanto que me conozco - dice- no soy sino una cosa que pienso; esto es todo lo que yo he mantenido en la segunda meditación" (VII. 355). Es decir, que esta meditación no ha demostrado que el yo sea sólo una cosa pensante. En realidad, no ha establecido tesis ontológica ninguna sino sólo una epistemológica.

De todas formas, volvemos a repetirlo, no se puede exonerar a Descartes de toda responsabilidad en la confusión, pues aparte de lo alambicado de su exposición, él podría haber facilitado las cosas a sus lectores si hubiera insistido, en aquella meditación, en que su indagación no era sobre lo que es el yo, sino sobre lo que puede conocerse de manera inmediata y con certeza inconcusa que es el yo; esto es: si hubiera dejado claro, en suma, que lo que allí se ventilaba no era qué es el yo intuido sino qué es lo intuible en el yo. Lo que no implica que en el yo no pueda haber algo no intuible.

\section{IV}

Pero volvamos, una vez más, a situarnos en la segunda meditación y en la primera, escuálida respuesta que Descartes da a esta cuestión. Sabemos ahora 
que lo que viene a decirnos es que, en tanto que intuible, el yo es una cosa que piensa, esto es: un espíritu, alma o mente, una razón o entendimiento. Una respuesta que al propio Descartes le parece inmediatamente excesivamente pobre. Quizás por ello, apenas una página después la completa: "Pero ¿qué es esto que yo soy? Una cosa que piensa. ¿Qué es una cosa que piensa? Una cosa que duda, que concibe, que afirma, que niega, que quiere, que no quiere, que imagina también, y que siente. Ciertamente no es poco si todas estas cosas pertenecen a mi naturaleza. Pero ¿por qué no habrían de pertenecerle?” (IX.22)

Ciertamente, no es poco. Desde luego es mucho más que lo que poco antes había dicho. Porque si un ser que fuera sólo razón o entendimiento parece inhumano, un ser humano puede empezar a reconocerse en este retrato del yo que le atribuye, además, voluntad, imaginación e incluso sentidos... Lo que no está nada claro es que el yo pueda ser todo esto sin tener que ser, también, algo más que pensamiento. De hecho, anteriormente había afirmado Descartes que al yo no le pertenecía el sentir porque... ¡no se puede sentir sin cuerpo! (IX. 21), y a esta conclusión más amplia sobre lo que el yo es llega Descartes después de haber advertido que para establecerla no hay que servirse de la imaginación porque ésta... ¡tiene que ver igualmente con lo corporal! ¿Entonces?

Entonces hay que empezar por aclarar por qué Descartes, que antes había expulsado del ámbito de lo intuible en el yo a los sentidos y a la imaginación, termina por reintroducirlos. La razón es sencilla: en tanto que actividades conscientes ${ }^{4}$ imaginar o sentir son tan intuitivamente cognoscibles como la existencia del yo que las realiza.

Comprendemos ahora cuál ha sido el criterio demarcatorio utilizado por Descartes para determinar, a esta altura de sus Meditaciones, qué pertenece al yo, a saber: todo aquello que pueda atribuírsele de una manera tan inconcusa y cierta, tan intuitiva, como su existencia. Por eso al yo no le pertenecen sólo el entendimiento o la razón sino también la voluntad, la imaginación y hasta los sentidos, pero no el cuerpo.

4 Un término, el de consciencia, que Descartes apenas utiliza en contextos epistemológicos y metafísicos y sólo cuando se expresa en latín. ¿La razón de ello? Probablemente el sentido moral que la palabra francesa "conscience" tenía y del que carecía la palabra latina "conscientia".

Por otra parte, si tenemos en cuenta que la conciencia es una propiedad no sólo epistemológica sino también ontológicamente privada "mis contenidos de conciencia sólo pueden pertenecerme y ser concienciados por mí" comprendemos que la equivocidad que corre a lo largo de toda la segunda meditación entre el qué o el quién es el yo de cuya existencia estamos seguros resulta, como ya adelantamos, irrelevante. El yo que descubre su identidad (genérica) consciente descubre, a la vez, su identidad (numérica) como el único sujeto posible de sus estados conscientes. 
De nuevo las tesis cartesianas vuelven a tener el respaldo de la gramática. Y es que la referencia garantizada que antes señalamos no es la única peculiaridad del pronombre de primera persona. Además es propio de éste poder aparecer en dos contextos gramaticales claramente diferentes: el de las oraciones en que la equivocación no cabe, sólo la insinceridad, el uso del yo como sujeto, como lo denominó Wittgenstein; y el de aquéllas en que la eventualidad del error no es absolutamente descartable, el uso del yo como objeto, en la terminología wittgensteiniana ${ }^{5}$. Oraciones como "siento escalofríos" o "me imagino a Atenea saliendo de la cabeza de su padre" pertenecen al primer tipo tanto como "dudo que venga" o "pienso salir esta noche"; mientras que oraciones en las que se atribuyen al yo propiedades físicas, como "mido un metro y setenta y seis centímetros" o "tengo el brazo roto", pertenecerían al segundo.

Tenemos, pues, y en resumidas cuentas, que si la imaginación y los sentidos se reconocen como pertenecientes al yo que se intuye en la segunda meditación ello es porque no puede caber duda, si estamos imaginando o sintiendo, de que estamos imaginando o sintiendo, aunque no podamos asegurar que a lo así imaginado o sentido corresponda algo fuera de nosotros.

Ahora bien, hagamos cuanta epoché queramos acerca de la verdad de lo imaginado o de lo sentido. El problema es si para ser conscientes de estar imaginando algo no deberemos ser conscientes también del algo que estamos imaginando; de si, por utilizar la propia caracterización cartesiana de lo que es imaginar, para ser conscientes de que estamos contemplando la figura o la imagen de algo extenso no deberemos ser conscientes también de la figura o la imagen extensa que estamos contemplando. Y si ello es así - ¿y cómo podría no serlo?- entonces en la propia mente anidan por lo menos algunos contenidos de una esencia -extensa- diferente de la esencia -inextensa- de los actos de la propia mente. Porque, como a la postre ya sabía Aristóteles, ver puede ser inextenso, pero lo visto no. Y otro tanto podríamos decir de las imágenes que nos figuremos.

5 Se ve en este punto paradigmáticamente la complejidad de la relación entre Wittgenstein y Descartes. Por una parte, el filósofo austriaco detecta el sustrato gramatical de las tesis cartesianas -el doble uso del "yo"- mientras que, por la otra, intenta desmarcarse de los planteamientos cartesianos defendiendo que en el contexto de las proposiciones incorregibles el "yo" no funciona referencialmente, tesis no sólo extraordinariamente implausible sino, además, cripto-cartesiana, pues como un análisis de los ejemplos de los que Wittgenstein se sirve, por ejemplo en el Blue Book, demuestra, parece concederle a Descartes que el "yo" sólo funciona como sujeto cuando se le atribuyen predicados psíquicos, y como objeto cuando se le atribuyen predicados físicos. 
Indudablemente, pues, la mente es consciente de ciertas ideas corpóreas. Algo en ella le impone la convicción de que hay algo distinto de ella. Las propias actividades psíquicas del yo le convencen de la existencia de lo corpóreo. Pero ¿qué tipo de convicción es ésta? No, dirá Descartes, una certeza metafísica; sólo, por consiguiente, una certeza moral que también es natural ${ }^{6}$.

En efecto, las ideas corpóreas de las que somos conscientes no nos pueden certificar metafísicamente la existencia de los cuerpos debido a su carácter oscuro; debido a que hay en ellas algo desconocido, algo que su contenido no puede garantizar, a saber: su causa. Ahora mismo soy consciente de un papel con ciertas inscripciones en él, pero resultan concebibles varias situaciones en que este estado consciente en mí no fuera provocado por un papel con ciertas inscripciones en él fuera de mí. No obstante, concede Descartes, es para nosotros natural remitir este tipo de ideas a sustancias que comparten su esencia -la extensión- con ellas. Es decir: a cuerpos. Es natural para mí, cuando tengo una experiencia como la que ahora tengo, creer que hay un papel con ciertas inscripciones justo enfrente de mí...

Enfrente de mí..., si recapacitamos sobre esta certeza comprendemos al punto que las ideas corpóreas no sólo nos convencen naturalmente de la existencia de cuerpos sino, lo que para nosotros es más importante, de la existencia de nuestro propio cuerpo. Y ello es así porque algunas de ellas, sentimientos como la sed, el hambre, el sueño, el placer, el dolor..., todo ese conjunto, en definitiva, de experiencias que la psicología actual suele agrupar bajo la categoría de la percepción interoceptiva, es natural remitirlos a, esto es localizarlos en, ese cuerpo particular que llamamos nuestro; pero incluso en las percepciones exteroceptivas o propioceptivas, y hasta en muchas de nuestras voliciones, está nuestro cuerpo causalmente involucrado de una forma privilegiada: vemos y nos ponemos a andar hacia donde queremos dirigirnos desde el lugar en que nuestro cuerpo está, y mediante sus ojos o sus piernas.

En suma, que la creencia de tener un cuerpo es natural para el yo; se le impone de una manera irreflexiva, inmediata, tanto cuando imagina y, sobre todo, siente, como en la mayor parte de las ocasiones en que quiere. Y esa creencia natural pasa para Descartes de tener una certeza moral a gozar de una metafísica cuando, procediendo metódicamente, se repara en que la naturaleza humana, siendo obra de Dios, no puede ser en este extremo defectiva (un filósofo ateo, o uno que no quisiera involucrar a Dios en estos negocios epistemológicos, habría de conformarse con decir que la certeza que tenemos de poseer un cuerpo es la máxima certeza moral que pueda tenerse; lo que no es poco, por cierto).

6 Quizás convenga en este punto recordar lo que, en la tercera meditación, dice Descartes a propósito de la naturaleza. Se lee allí: "Cuando digo que me parece que esto me es enseñado por la naturaleza, entiendo por esta palabra, naturaleza, una cierta inclinación que me lleva a creerlo, y no una luz natural que me haga conocer que es verdad." (IX. 30). 


\section{VI}

¿Qué es entonces el yo según Descartes? Nuestra intuición responde, sin duda un espíritu. Pero también, añade nuestra naturaleza independientemente de que se la justifique metafísicamente o no, con toda certeza un cuerpo. Yo mismo, todo entero, concluye Descartes, estoy pues compuesto de cuerpo y alma ${ }^{7}$. Con lo que el prejuicio natural por el que nos consideramos un ser humano, despachado en la segunda meditación, cuando se trataba de precisar qué es lo intuible en el yo, es rehabilitado en la sexta, cuando se establece un juicio definitivamente fundado acerca de la naturaleza del yo.

Podríamos ahora volver con más rotundidad sobre el argumento que Kripke -vocero en este punto de la historia efectual- atribuye a Descartes para decir que éste no puede ser un argumento cartesiano por la sencilla razón de que su conclusión -recuérdese: que el yo de Descartes no es su cuerpo- no es una conclusión cartesiana. El yo de Descartes, que es el yo que ha cumplido la meditación metafísica, es el yo de un ser humano, cuya identidad es, de facto, la identidad del propietario de todos aquellos pensamientos de los que tiene conciencia y del cuerpo del que algunos de aquellos pensamientos (los que son producto de la imaginación y los sentidos, pero también bastantes de sus voliciones) le hacen consciente de una manera privilegiada ${ }^{8}$.

Esta conclusión puede chocar con las exégesis más descuidadas y tópicas de la antropología cartesiana pero debe notarse que no niega el dualismo que se suele señalar como característica más destacada de la misma. El yo es único, pero no deja de ser un sujeto propietario de dos cosas diferentes: pensante la una, extensa la otra; un sujeto compuesto de dos sustancias esencial y realmente distintas. Lo que inmediatamente plantea el viejo problema, al que ya se enfrentaron los filósofos cristianos del medioevo, de cómo entender la unidad del hombre, del yo, concreto. Y en cuanto se considera lo que Descartes dice al respecto vuelven a encontrarse nuevas disculpas para la mala interpretación kripkeana.

\section{VII}

En efecto, el pensador francés termina por suscribir una concepción dualista del ser humano como un sujeto compuesto (Cf. por ejemplo las Notae in

7 “...moi-même tout entier... je suis composé du corps et de l'âme.../...me totum...ex corpore et mente sum compositus...” IX. 65; VII. 81

8 Descartes sostiene la idea de que el alma es consciente de su unión con el cuerpo en diferentes lugares de su correspondencia. Cf. por ejemplo las cartas a Elisabeth del 28 de junio de 1643 o la carta a Arnauld del 29 de julio de 1648. III. 649 y V. 222, respectivamente. 
programa. VIII. 351) de dos sustancias esencial y realmente distintas que no se hallan en pie de igualdad, pues como él mismo afirma, en los sujetos compuestos de varias sustancias, frecuentemente hay una que es la principal (VIII. 351).

Pues bien, siguiendo en esto la tradición scotista, Descartes considera que en ese compuesto que es el hombre, el privilegio y, por tanto, el papel de auténtico principio de individuación, corresponde al alma (Cf. por ejemplo, la carta al padre Mesland de 1645 o 1646. IV. 346). Lo que significa que aunque ciertamente la persona humana, el ego, es el conjunto formado por alma y cuerpo, esencialmente es el alma, pues sólo su existencia, pero no la del cuerpo, puede conocerse con la misma inmediatez con que se conoce la existencia del yo, esto es: intuitivamente; y debiéramos recordar que para el pensador francés es la intuición la facultad que nos hace presente la esencia de los entes.

Este conocimiento, por otra parte, piensa Descartes que podría obtenerse aun a pesar de un absoluto desconocimiento del mundo. Y, correlativamente, piensa igualmente que este alma, esencia del yo, podría seguir existiendo con independencia del mundo y, por lo tanto, del propio cuerpo. Claro que, en tal eventualidad, existiría fuertemente menguada en sus facultades, pues habría de perder todas aquellas (y los correspondientes estados de conciencia) de que disfruta o padece por su unión con éste: la imaginación, los sentidos, tanto externos como internos, las pasiones... lo que legitima la pregunta de si en estas condiciones el yo que actualmente somos todavía podría identificarse con este alma castrada, con esta parte esencial de la misma esencia -de la conciencia-, no muy diferente de aquella mente reducida a una pura razón de la que Descartes, quien advertía que se estaba expresando con precisión, habló en cierto punto de su segunda meditación 9 .

Luego si la posición de Descartes está mal formulada cuando, sin más matizaciones, se afirma que para él el yo no era el cuerpo sino el alma, parecería que nada podría objetarse a quien interpretara que su posición lo que defiende es que el yo, aunque compuesto de alma y cuerpo, tiene por esencia sólo a la primera.

De hecho, podrían aducirse de nuevo razones de por qué esta tesis no es en absoluto baladí. Al fin y al cabo, las personas parecen tener características que concuerdan mejor con las de la mente que con las del cuerpo. Así, por ejemplo, consideramos que la subjetividad es una característica especialmente distintiva de las personas, pero la subjetividad es una propiedad intrínseca de una mente definida, como hemos visto, por la conciencia, mientras que característica de los cuerpos es su objetividad.

9 Cf. la sexta meditación, en la que Descartes afirma que ni la imaginación, ni los sentidos formarían parte de la esencia más propiamente dicha del yo. IX. 62. Cf. también la carta al padre Gibieuf del 19 de enero de 1642 y la que dirige a Morus de agosto de 1649. III. 479 y V. 402 respectivamente. 
Del mismo modo, consideramos que la identidad de las personas es determinada y no convencional, en tanto que la de los cuerpos parece pasto propicio para alimentar la sorites. ¿Cuántas piezas del barco de Teseo, por remitirnos al famoso ejemplo de Hobbes, podemos sustituir antes de que tengamos que hablar de otro barco? La pregunta no tiene respuesta determinada a menos que estipulemos alguna convención para zanjarla. Pero la pregunta de si Edipo era o no aquel niño, hijo de Layo y Yocasta, que fue abandonado en el monte Citerón debe tener una respuesta precisa que no puede estipularse convencionalmente; lo mismo que la pregunta de si fui yo quien tuvo o no determinada experiencia consciente.

O también, consideramos que las personas no admiten división, lo que concuerda bien con el carácter inextenso atribuido por Descartes al espíritu pero se contradice con la naturaleza extensa, y por lo tanto esencialmente divisible, que el pensador francés atribuye a los cuerpos.

En resumidas cuentas: que la persona está más cerca tanto por sus características lógicas -la naturaleza de su identidad-cuanto por las epistemológicas -la manera subjetiva de conocerse, la autoconciencia- y ontológicas -su indivisibilidad, por ejemplo- del alma que del cuerpo.

\section{VIII}

Y sin embargo, siendo todo esto verdad, siendo verdad que Descartes defiende la tesis de la real distinción entre alma y cuerpo y el carácter esencial que la primera pero no el segundo tiene para el yo, no lo es menos que parece bien consciente de lo peligroso que sería deslizarse hasta la concepción reduccionista y así, a pesar de todo, cuando aborda el problema de la relación entre mente y cuerpo en el sujeto, en el yo particular que componen, insiste siempre en calificarla como "estrechísima".

El hombre no es para él, a diferencia de para Regius, un ens per accidens sino per se, cuya alma y cuerpo están unidos real y sustancialmente, hasta el punto de que, por relación al todo que conforman, bien se les puede considerar como sustancias incompletas, de modo semejante a como lo es una mano por relación al cuerpo del que forma parte (IX.173). Lo que le diferenciaría tanto de los platónicos, para quienes el hombre sería sólo un espíritu sirviéndose de un cuerpo, cuanto de los herejes cátaros, para quienes el hombre sería un ángel encerrado en un cuerpo ${ }^{10}$.

10 “...los sentimientos de dolor y todos los otros de naturaleza semejante no son puros pensamientos del alma distinta del cuerpo, sino percepciones confusas de este alma que está realmente 
Esta última observación nos permite comprender que la tesis reduccionista acerca de la naturaleza del yo que hemos venido cuestionando como interpretación adecuada de la posición cartesiana al respecto, sería más correcto calificarla como una teoría platónica. Y también nos permite entender algunas de las razones que Descartes pudo tener para no suscribirla. Al fin y al cabo, la concepción platónica de las relaciones entre alma y cuerpo, según la cual el alma mantendría con el cuerpo una relación análoga a la que tiene el piloto con su navío ${ }^{11}$, deja lugar para la metempsicosis -una metempsicosis cuya inteligibilidad algunos de los que hoy se tienen por cartesianos esgrimen como evidencia favorable a sus posiciones-; tesis que sin duda debió pesar en el ánimo de los inquisidores cuando condenaron a Bruno por haberla sostenido... y muy probablemente en el de Descartes a la hora de rechazarla (Cf. IX. 64; también la carta a Regius de mediados de diciembre de 1641. III. 460).

Pero evidentemente, y por lo que ahora ya sabemos, Descartes no sólo tenía razones de prudencia teológica para oponerse a esta concepción reduccionista del yo y a la correlativa concepción accidental de las relaciones psico-físicas. Su razón fundamental para oponerse a la misma es la naturaleza de nuestra propia experiencia consciente, pues ella nos proporciona tanto la certeza natural de que en la sensación y en la imaginación somos afectados por los cuerpos que nos rodean y por el nuestro eminentemente, cuanto la de que nuestra conciencia actúa sobre este cuerpo en los movimientos del mismo que realizamos voluntariamente. En suma, que para Descartes la real y estrechísima unión del alma con el cuerpo no es algo que la filosofía deba demostrar sino un dato incontrovertible -algo que experimentamos todos los días, escribe en las respuestas a las objeciones de Arnauld (Cf. IX. 177)- que, a lo sumo, la filosofía habría de explicar.

Y es que para Descartes ocurre con la real y estrechísima unión del alma con el cuerpo algo parecido a lo que acontece con nuestra libertad. En uno y otro caso se trata de evidencias inmediatas, indiscutibles, que de ningún modo pueden ni deben sacrificarse a las exigencias del sistema, aunque no sepamos cómo reconciliarlas con ciertas verdades metafísicas: la tesis de la real distinción, en un caso, la del carácter total de la causalidad divina, en el otro.

unida al cuerpo; pues si un ángel estuviera unido al cuerpo humano no tendría los sentimientos como nosotros, sino que sólo percibiría los movimientos causados por los objetos exteriores y por ello diferiría de un verdadero hombre". Carta a Regius de enero de 1642. (III. 493).

11 Aunque la idea de que el alma se relaciona con el cuerpo como el piloto con su navío, a la que Descartes alude para criticarla en la sexta meditación, es mentada por Aristóteles en su Tratado acerca del alma (Cf. 413a 8) se la solía atribuir, sin embargo, a Platón. 


\section{IX}

Quizás sea el momento oportuno de hacer cierta recapitulación. Descartes parece haber tenido que afrontar un dilema, y ello tanto por razones digamos externas cuanto, lo que es más importante, por razones internas a su propio sistema.

Su deseo de agradar a los teólogos de la Sorbona, a quien no lo olvidemos están dedicadas las Meditaciones, le obligaba a tener que "demostrar" la inmortalidad del alma o, al menos, lo que dejaba la vía expedita para que tal inmortalidad fuera posible, su real distinción con respecto al cuerpo; pero sin dejar paso a la peligrosa idea de la transmigración de las almas.

Por otra parte, una serie de consideraciones lógicas, epistemológicas y ontológicas (el carácter determinado y no convencional de la identidad del sujeto de conciencia, así como su indivisibilidad y su naturaleza subjetiva, propiedades todas ellas compartidas con las personas y con el tipo de identidad que les atribuimos) bien enraizadas, por lo demás, en la gramática de nuestro lenguaje sobre lo mental (la referencia garantizada del pronombre en primera persona, el doble uso, como sujeto y como objeto, a que se presta) le llevaban en la dirección de un dualismo cuya radicalidad, no obstante, se veía obligado a matizar para hacer justicia a la naturaleza de nuestra propia experiencia consciente, ya que no sólo ella nos empuja a creer naturalmente que somos seres encarnados en un mundo de cuerpos sino que basta una pequeña reflexión para percatarse de lo drásticamente que aquella conciencia cambiaría si de ella hubiéramos de descontar todos aquellos estados que asociamos con la corporalidad: las sensaciones, las imaginaciones, las pasiones ${ }^{12}$... hasta el punto de que bien podríamos preguntarnos si seguiría siendo personal, desde luego no parece que pudiéramos seguir catalogándola de humana.

Vemos, pues, que el dilema de Descartes no es gratuito, tiene profundas razones porque profundas son tanto las razones que nos tientan a reducir el yo al alma cuanto las que nos empujan a no ceder a esta tentación y a considerarlo como una unidad psicofísica. Su manera de lidiar con tan conflictiva situación parece haber sido la de defender que el yo es el resultado de la unión estrechísima, cuasi-sustancial dice a veces, sencillamente sustancial otras, de alma y cuerpo pero, a la vez, apostillar que la esencia de ese yo la constituye sólo el alma.

12 Debe recordarse que para Descartes las pasiones del alma son el resultado de la afectación que produce en esta la acción del cuerpo. De modo que sin cuerpo el alma no tendría más pasiones que las que ella misma, con su actividad, pudiera provocarse. Sin cuerpo, por ejemplo, habría de desaparecer la pasión sexual. 
¿Qué debemos decir de esta solución? ¿Consigue mantener un equilibrio estable? No lo creo. Y creo que tampoco el propio Descartes estaba completamente satisfecho con la misma.

\section{$\mathrm{X}$}

Al respecto, resulta de lo más significativa su correspondencia con la princesa Élisabeth. De hecho, Descartes terminará en ella por reconocer la incompatibilidad de aquella verdad indiscutible que como hemos visto es la de la estrecha unión del alma con el cuerpo con la verdad metafísica de su distinción real; y así, después de admitir cierta negligencia en sus obras publicadas a la hora de explicar esta unión -otra disculpa más a favor de las interpretaciones platónicas de sus puntos de vista- pasa a conferir a aquella unión el estatuto de una noción primitiva que, como tal, no puede ser explicada por otras nociones, y en concreto, no puede ser explicada por las nociones de alma y cuerpo separadamente consideradas (Cf. Carta a Élisabeth del 21 de mayo de 1643. III. 665-666).

Esta unión se comprende, añade, por los sentidos y la vida -de ahí que pudiéramos ahora agregar nosotros que aquella verdad, la de la unión del alma con el cuerpo, no es sólo incontrovertible sino también vital-y una perspectiva metafísica o filosófica no puede dar cuenta de ella, esto es: de nuestra experiencia de nosotros mismos como una única persona (Cf. Carta a Élisabeth del 28 de junio de 1643. III. 691 y siguientes).

Lo que quiere decir que el racionalista Descartes termina, como luego habría de hacer el empirista Hume, por tomar clara conciencia de los límites de su metafísica y de su sistema para dar cuenta de nuestra unidad como personas y, por ello mismo, del mundo vivido. Pero no sólo hace esto, también diagnostica el origen del problema y de semejante diagnóstico bien podríamos nosotros sacar alguna sugerencia sobre cómo, al menos, volverlo a afrontar.

En efecto, la dificultad, diagnostica Descartes, estriba en que el espíritu humano no es capaz de concebir a la vez y distintamente la distinción entre alma y cuerpo, por una parte, y su unión, por la otra; pues para hacer esto último es preciso concebir cuerpo y alma como una sola cosa, mientras que para hacer lo primero es preciso concebirlas como dos. Y es que concebir la unión que hay entre dos cosas, nos ha dicho previamente, es concebirlas como una sola cosa.

Si hemos de pensar la unión entre alma y cuerpo, esa unión incontestable, de la que la vida da testimonio a cada instante, debemos entonces considerar al alma y al cuerpo como una sola cosa. Sí, pero ¿cómo? Quizás, nos atrevemos a sugerir, considerando al alma como corpórea y al cuerpo como animado. De 
hecho, justamente así es como no se pensó el cuerpo en la segunda meditación, cuando Descartes negó que el mismo formara parte de lo que se intuye en el yo. Quizás convenga recordar el texto:

"Me consideré primeramente -nos dice- como teniendo una cara, manos, brazos, y toda esta máquina compuesta de huesos y carne, tal y como aparece en un cadáver, la cual designaba con el nombre de cuerpo... Por lo que hacía al cuerpo, no dudaba en absoluto de su naturale$\mathrm{za}$, pues pensaba conocerlo muy distintamente, y, si lo hubiera querido explicar siguiendo las nociones que tenía, lo hubiera descrito de la manera siguiente: por el cuerpo entiendo todo lo que puede ser limitado por alguna figura, que puede estar comprendido en algún lugar y llenar un espacio de tal manera que excluya a todo otro cuerpo; que puede ser sentido o por el tacto, o por la vista, o por el oído, o por el gusto, o por el olfato; que puede ser movido de múltiples maneras, no por sí mismo, sino por alguna cosa ajena por la cual sea tocado o de la que reciba la impresión. Pues de tener en sí la potencia de moverse, de sentir y de pensar, no creo que se debieran atribuir estas ventajas a la naturaleza corporal; al contrario, me extrañaba mucho ver que facultades semejantes se encontraban en ciertos cuerpos". (IX.20-21)

Llama la atención la morbosidad de la concepción del cuerpo humano que aquí esboza Descartes, y que hace recordar a las descripciones, recogidas por la literatura clínica, que del mismo dan algunos esquizoides. Como si hubieran sufrido la mirada de una extraña Gorgona, los cuerpos humanos han quedado mecanizados, cadaverizados, reducidos a sus propiedades geométricas o dotados de aquellas propiedades empíricas que comparten con los cuerpos inertes. Despojados de cualquier espontaneidad -de lo que Aristóteles entendía por physis: un principio interno de movimiento o reposo- son comprendidos como simple materia.

Es difícilmente creíble que ésta pueda ser la concepción natural, pre-teórica, que los seres humanos se hacen de sus propios cuerpos (o en general, de los cuerpos vivos). Más bien, los prejuicios cartesianos en este punto parecen asumir la objetivación del mundo natural que imponía la por entonces naciente física matemática.

Retengamos, no obstante, esta primera conclusión. Esta objetivación, esta consideración mecánica del cuerpo humano, por más útil que pueda resultar para ciertos propósitos, como por ejemplo el de desarrollar una medicina eficaz, nos va a dificultar la comprensión de esa unidad psicofísica que caracteriza nuestra vida humana ${ }^{13}$. Antes por el contrario nos va a hacer deslizarnos por la senda del dualismo y del reduccionismo. Dado que sabemos con toda certeza que

13 En el prefacio de su inacabada Descripción del cuerpo humano, en el que el mismo es presentado como un reloj, Descartes anuncia las muchas ventajas que para la medicina, "tanto para curar las enfermedades cuanto para prevenirlas, e igualmente para retardar el curso de la vejez", reportará el estudio del cuerpo así objetivado. Cf. XI.223. 
no somos máquinas, aunque tengamos cuerpos, si estos no son sino máquinas no podemos ser nuestro cuerpo. Luego deberemos ser algo más que, y algo diferente de, un cuerpo ${ }^{14}$.

Pero esta no es la única forma posible de considerar el cuerpo. Descartes lo sabía bien. En una carta que dirige al padre Mesland el 9 de febrero de 1645, le escribe:

Primeramente considero qué es el cuerpo de un hombre, y encuentro que esta palabra de cuerpo es muy equívoca; pues, cuando hablamos de un cuerpo en general, entendemos una parte determinada de la materia, y el conjunto de la cantidad de la que el universo está compuesto, de modo que no se sabría quitar tan poco como sea de esta cantidad sin que juzgáramos inmediatamente que el cuerpo es menor y ya no más entero, ni cambiar ninguna particula de esta materia, sin que pensáramos que después el cuerpo ya no es más totalmente el mismo, o idem numero. Pero cuando hablamos del cuerpo de un hombre, no entendemos una parte determinada de materia, ni que tenga una magnitud determinada, sino que sólo entendemos toda la materia que está en conjunto unida con el alma de este hombre; de modo que aunque esta materia cambia, y su cantidad aumenta o disminuye, siempre creemos que es el mismo cuerpo, idem numero, mientras permanezca junto y unido sustancialmente a la misma alma; y creemos que este cuerpo es todo entero, mientras que tenga en sí todas las disposiciones requeridas para conservar esta unión... no pienso que haya ninguna particula de nuestros miembros que permanezca el mismo numero un solo momento, aunque nuestro cuerpo, en tanto que cuerpo humano, permanezca siempre el mismo numero mientras está unido a la misma alma. E igualmente, en este sentido, él es indivisible... (IV. 166-7)

Es decir, que cuando consideramos el cuerpo como un cuerpo humano ya no lo consideramos como mera extensión ni como una máquina sino como un cuerpo animado, y dotado por ello de un tipo de identidad diferente a la identidad convencional y, a veces, indeterminada de las máquinas o a la excesivamente rígida de las meras agregaciones de materia. Antes al contrario, los cuerpos humanos, en tanto que tales, son entidades genidénticas, entidades que pueden preservar su genuina identidad a través del cambio... como ocurre con la identidad de los seres vivos.

Por lo que hace a la concepción corpórea del alma Descartes pensó que la analogía de la misma con la gravedad tal y como la concebían los filósofos peripatéticos y escolásticos, esto es como un accidente real que, disperso por todo el cuerpo, sería la causa de su movimiento, podría ser iluminadora (Cf. la ya mentada carta a Élisabeth del 28 de junio de 1643; o la carta a Arnauld del 29 de julio de 1648. V. 222-3).

14 Aunque también cabe el razonamiento justamente opuesto: dado que no somos más que un cuerpo, y este es una máquina, no somos más que máquinas. Es importante percatarse de cómo los reduccionismos son contrarios antes que contradictorios. Ambos se pueden nutrir de una misma premisa básica. Y ambos pueden resultar, por lo tanto, igualmente erróneos. 
La verdad es que encuentro esta sugerencia de Descartes mucho menos acertada que sus reflexiones acerca de lo que pueda significar entender el cuerpo como animado. Pero quizás en Aristóteles, a quien curiosamente termina por apuntar Descartes, podamos, después de todo, encontrar una clave fructífera. Al fin y al cabo si entender el cuerpo como animado pasó por entenderlo como una realidad viva otro tanto podríamos decir del alma. Pues bien, para el de Estagira el alma, sin la que un ser vivo no sería tal, no es ninguna realidad "interna", "fantasmagórica" o "inobservable". Más bien, siendo la entelequia primera de un cuerpo natural organizado, según reza la célebre definición del De Anima (Cf. 412 b 6-8), se trata de una realidad que se actualiza en la praxis, en la manera en que un ser vivo se comporta.

Si antes veíamos cómo el tratamiento que Descartes daba del cuerpo en la segunda meditación auspiciaba el dualismo y el reduccionismo, otro tanto podemos decir ahora de la manera como trata el alma.

Como es bien sabido, por reiteradamente señalado, la concepción cartesiana del alma como una realidad pensante tiene un claro precedente en la teoría agustiniana de la mente como dotada de un sensus interior. Lo que quizás ya no se señale tan a menudo es que ambas pueden retrotraerse, a través de un itinerario que desde Plotino pasaría por la teoría estoica de la synaísthesis, hasta el mismo Aristóteles y su teoría de la koiné aísthesis.

En un texto de la Ética nicomaquea, de hecho, puede leerse: “...el que ve se da cuenta de que ve, y el que oye de que oye, y el que anda de que anda e, igualmente, en los otros casos hay algo en nosotros que percibe que estamos actuando, de tal manera que nos damos cuenta, cuando sentimos, de que sentimos, y cuando pensamos, de que estamos pensando; y percibir que sentimos o pensamos, es percibir que existimos" $\left(1170^{\mathrm{a}} 29-34\right)$.

Pues bien, a pesar de este claro precedente aristotélico de la cartesiana concepción del pensamiento ${ }^{15}$, hay al menos dos diferencias importantes que separan a Descartes de Aristóteles en este punto. La primera, significativa pero menos importante para la cuestión que nos traemos entre manos, es que a diferencia de Aristóteles y también de San Agustín, quienes entendían el sentido común y el sentido interior como una facultad común a hombres y animales, Descartes viene a coincidir con Plotino al entender que el pensamiento es un signo distintivo de los primeros, quizás porque entiende que esa apercepción que el pensamiento nos proporciona de nosotros mismos es más de índole intelectual que sensorial.

La segunda, y quizás en esto estribe la diferencia fundamental de Descartes no sólo con Aristóteles sino con toda la tradición que le precede, porque

15 Compárese el texto aristotélico con la definición que del pensamiento se encuentra en Los principios de la filosofía. VIII.7 
mientras el de Estagira sobreentiende que el sujeto conoce de su existencia conociendo el mundo, actuando en el mundo, para Descartes la certeza de sí que tiene el sujeto no quedaría empañada en lo más mínimo porque a ese yo sólo le pareciera (es decir: le pareciera falsamente) conocer el mundo o actuar en el mundo. De este modo, Descartes dota al sujeto de ese pensamiento, definido como conciencia, de una suficiencia ontológica que constituye una de las marcas distintivas de la sustancia (Cf. IX. 47).

Pues bien, es justamente de esta reificación de la conciencia, paralela a la mecanización del cuerpo, de lo que debiéramos huir si es que queremos pensar corpóreamente el alma, pues lo que esto significa no es que debamos asumir ningún tipo de reduccionismo físico que viniera a identificar el pensamiento con algún tipo de evento físico ${ }^{16}$, sino que debemos ver la conciencia no como una realidad encapsulada sino como una realidad relacional que sólo puede llegar a ganarse en el trato con el mundo.

Sospecho que en esta materialización del alma, como en aquella espiritualización del cuerpo, podemos encontrar claves fructíferas para pensar de nuevo el problema de la naturaleza de nuestra identidad como personas y la relación entre mente y cuerpo. Para no quedar atrapados, en definitiva, en el dilema de Descartes.

16 Una vez más el reduccionismo materialista como contrapartida casi exacta del reduccionismo espiritualista. Contrario a él, tan erróneo e incapaz como él para dar cuenta de la experiencia de nuestra unidad psico-física. 